\title{
Low Symbiodiniaceae diversity in a turbid marginal reef environment
}

\author{
E. G. Smith ${ }^{1,2}\left(\right.$ D $\cdot$ A. Gurskaya ${ }^{1}$ - B. C. C. Hume $^{3}$ (D) C. R. Voolstra $^{3,4}$ (D)

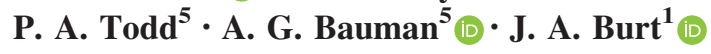

\begin{abstract}
The coastal waters of Singapore support coral reefs that are biodiverse but characterized by high turbidity and sedimentation. Here, we used internal transcribed spacer two (ITS2) amplicon sequencing to investigate the Symbiodiniaceae communities associated with this marginal reef system, as turbid reefs may serve as potential refugia from future thermal stress. Using the analytical framework SymPortal, we identified a predominance of Cladocopium among the five coral species studied across six reef sites. Durusdinium was present in comparatively lower abundances and was composed of multiple Durusdinium trenchii strains. In contrast to other marginal environments, the Cladocopium communities exhibited low diversity and lacked the host-specificity of strains
\end{abstract}

E. G. Smith esmit245@uncc.edu

1 Center for Genomics and Systems Biology, New York University Abu Dhabi, PO Box 129188, Abu Dhabi, UAE

2 Department of Biological Sciences, University of North Carolina at Charlotte, Charlotte, NC 28262, USA

3 Red Sea Research Center, Division of Biological and Environmental Science and Engineering (BESE), King Abdullah University of Science and Technology (KAUST), Thuwal, Saudi Arabia

4 Department of Biology, University of Konstanz, 78457 Konstanz, Germany

5 Experimental Marine Ecology Laboratory, Department of Biological Sciences, National University of Singapore, Singapore 117558, Singapore reported elsewhere. Nevertheless, we identified a sitespecific strain across three species, which was supported by sequencing of the non-coding region of the psbA minicircle $\left(\mathrm{psbA}^{\mathrm{ncr}}\right)$. The overall low diversity of the symbiont communities suggests that, although Singapore's reefs may provide habitat for a diverse coral assemblage, the strong selective pressure exerted by the prevalent turbidity likely limits the diversity of the associated symbiont community.

Keywords Symbiodiniaceae - Marginal reefs · ITS2 . Singapore

\section{Introduction}

Reef-building corals have experienced widespread declines in recent decades due to a variety of natural and anthropogenic stressors (Bruno and Selig 2007; Hoegh-Guldberg et al. 2007; Wilkinson 2008; De'ath et al. 2012). Understanding the effects of extreme environmental conditions on reef-building corals is therefore paramount for predicting how future ocean conditions may impact coral populations (Kleypas et al. 1999; Camp et al. 2018). Studies of corals in marginal habitats provide a unique opportunity to elucidate the mechanisms that underpin the ecological resilience of reef communities at the extremes of their environmental tolerances.

One critical aspect of coral biology that is impacted by environmental conditions is the coral-algal symbiosis (Hennige et al. 2010; Lesser et al. 2010; Hume et al. 2013, 2015, 2016; Howells et al. 2016; Smith et al. 2017c). The symbiotic dinoflagellates of the family Symbiodiniaceae (LaJeunesse et al. 2018) help support the coral host's metabolic demands through the translocation of photosynthetically fixed carbon (Muscatine and Porter 1977). 
This relationship is highly sensitive to changes in environmental variables, as evidenced by the phenomenon of coral bleaching, whereby symbiosis breaks down under stressful conditions (Glynn 1983; Brown 1997). Symbiont communities in coral hosts from marginal environments have shown increased presence of stress-tolerant Durusdinium genotypes, novel Cladocopium types, and/or high symbiont diversity (Fabricius et al. 2004; Hennige et al. 2010; Wicks et al. 2010; Oliver and Palumbi 2011; Hume et al. 2015; Smith et al. 2017b, c; Ziegler et al. 2017). In marginal environments dominated by Durusdinium, the stress-tolerant symbiont Durusdinium trenchii is commonly encountered (LaJeunesse et al. 2010; Keshavmurthy et al. 2014). Alternatively, in other extreme environments, D. trenchii appears to be outcompeted by different lineages, for example, the Cladocopium thermophilum lineage in the thermally extreme southern Persian/Arabian Gulf (D'Angelo et al. 2015; Hume et al. 2015, 2016; Smith et al. 2017a, c; Howells et al. 2020). Recent advances have shown that this lineage has diversified into host-specific strains (Smith et al. 2017b). This juxtaposition of high symbiont diversity on reefs with low coral species diversity has also been documented in other marginal environments (LaJeunesse et al. 2008; Wicks et al. 2010).

While low coral species diversity is a common feature of many marginal reef environments, it is not always the case. Singapore's reefs are an excellent example of a system that is characterized by high coral species diversity, with $>250$ species recorded despite environmentally stressful conditions (Huang et al. 2009). Singapore's reefs have been subject to decades of extensive anthropogenic impacts from large-scale land reclamation, coastal development, and shipping activities (Guest et al. 2016b). As a consequence, Singapore's reefs are heavily impacted by sedimentation and high turbidity levels, restricting the euphotic zone to the upper $8 \mathrm{~m}$, even at offshore sites (Todd et al. 2004). While coral hosts can exhibit adaptation/acclimatisation strategies to low light (e.g., Todd et al. 2004; Stambler and Dubinsky 2005; Smith et al. 2017d), the low light environment is also likely to affect the associated symbiont communities (Toller et al. 2001; Iglesias-Prieto et al. 2004; Bongaerts et al. 2010). However, as temperature and light act synergistically in thermal bleaching, the low irradiance on turbid reefs can help reduce the local incidence of bleaching (Cacciapaglia and van Woesik 2016; Morgan et al. 2017). This has led to the hypothesis that turbid reefs may serve as important refugia from thermal stress events (Cacciapaglia and van Woesik 2016; Morgan et al. 2017; Camp et al. 2019) and, therefore, it is essential to characterize the symbiont diversity associated with these marginal environments. Previous work has found both Cladocopium- and Durusdinium-containing assemblages in Singapore (Reimer and Todd 2009; Guest et al. 2016a; Tanzil et al. 2016; Poquita-Du et al. 2020). However, these studies have been limited in their ability to resolve the full diversity of Symbiodiniaceae present due to limited sample sizes and the use of less powerful methods of genotypic delineation (e.g., direct sequencing, DGGE, OTU clustering). As such, the Symbiodiniaceae communities in Singapore, and the region in general, remain largely understudied.

Here, we use high-resolution analyses of next generation sequencing-based internal transcribed spacer two (ITS2) amplicons supported by sequencing of the chloroplastic psbA non-coding region $\left(\mathrm{psbA}^{\mathrm{ncr}}\right)$ to investigate the diversity and structure of the Symbiodiniaceae communities associated with these marginal, yet highly diverse, reefs.

\section{Materials and methods}

Five locally abundant coral species [Pectinia alcicornis (Saville Kent 1871), Merulina ampliata (Ellis and Solander 1786), Platygyra daedalea (Ellis and Solander 1786), Podabacia crustacea (Pallas 1766) and Pachyseris speciosa (Dana 1846)] were sampled across six fringing reefs in the Southern Islands of Singapore (Fig. 1). Samples were identified according to Veron et al. (2015) and Huang et al. (2014). Within each site, a small coral fragment (1-2 $\mathrm{cm}^{2}$ ) was collected from 15 individual colonies for each species at 3-4 m depth. Samples were placed in individual zip-lock bags and transferred to salt-saturated DMSO immediately following each dive. The samples were stored at $4{ }^{\circ} \mathrm{C}$ prior to DNA extractions. DNA extractions and ITS2 amplicon library preparation [using the Sym-Var primer set (Hume et al. 2018b)] were performed according to an established protocol as previously described (ESM Supplementary Methods; Smith 2017b). Sequencing was performed on an Illumina MiSeq at the New York University Abu Dhabi Sequencing Core facility using the 600-cycle kit.

Raw sequencing reads were demultiplexed using the process_radtags module of Stacks (Catchen et al. 2013). Demultiplexed reads were then loaded into SymPortal (Hume et al. 2019). SymPortal uses the co-occurrence of ITS2 intragenomic variants within samples to identify Symbiodiniaceae profiles, analogous to DGGE 'types' but exploiting the greater sequencing depth and sensitivity of amplicon approaches (Hume et al. 2019). Sequencing data are analysed by SymPortal using a standardized approach across all analytical steps to ensure reproducibility and transferability across studies (Hume et al. 2019). Paired FASTA files are quality filtered in mothur (Schloss et al. 2009), screened for Symbiodiniaceae sequences within the range $184-310 \mathrm{bp}$, and then collapsed to associate the 


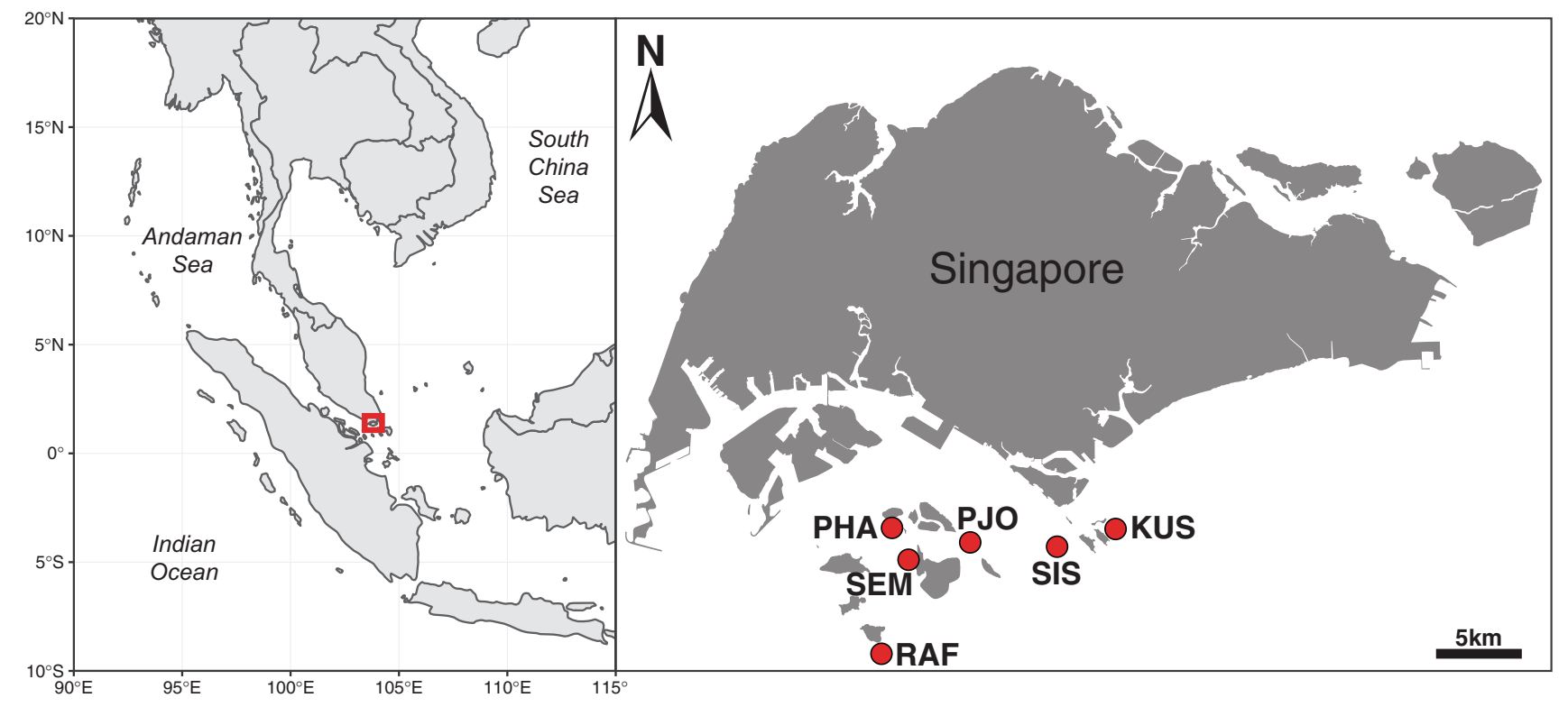

Fig. 1 Location of study site. Left: The geographic situation of Singapore. Right: Locations of the six sampling sites (RAF, Raffles; PHA, Pulau Hantu; SEM, Pulau Semakau; PJO, Pulau Jong; SIS, Sisters' Island; KUS, Kusu)

rarest variants to more common variants on a sample by sample basis using minimum entropy decomposition (Eren et al. 2015). After quality control, SymPortal calculates the presence and relative abundance of ITS2 profiles within each Symbiodiniaceae genus through the identification of co-occurring defining intragenomic variants (DIVs) within samples, and those in the existing database. As different combinations of DIVs form distinct ITS2 profiles, the number of ITS2 profiles identified can exceed the number of DIVs reported in a set of samples. The naming of the profiles reflects the DIVs present in the profile, in order of their relative abundance. For example, C27-C21-C27a describes a symbiont genotype that contains the ITS2 sequences C27, C21, and C27a, where C27 is the most abundant ITS2 sequence in that symbiont. Where two or more DIVs are separated by the "/ character, this signifies that they are co-dominant in that profile.

Statistical analyses were performed using the vegan package (v.2.5-6; Oksanen et al. 2019) in R (v.3.6.2; R Core Team 2019). The proportion of different Symbiodiniaceae genera and ITS2 profiles within samples were arcsine square-root transformed before the calculation of a Bray-Curtis distance matrix using the vegdist command. We tested for significant differences among host species and sites using permutational multivariate analysis of variance (PERMANOVA) via the adonis function. As differences in dispersion among groups can impact PERMANOVA analyses, we also performed an analysis of multivariate homogeneity of dispersion (variance) using betadisp. By evaluating the degree of imbalance in group sample sizes and variance ratios in relation to the simulations of Anderson and Walsh (2013), we concluded that our PERMANOVA results were robust to Type I errors caused by heterogeneous dispersions (see ESM: Supplementary Methods and Results; Hume et al. 2020).

To validate the identification of a novel symbiont type found at Sisters' Island, the $\mathrm{psbA}^{\mathrm{ncr}}$ marker was analysed. The psbA $^{\text {ncr }}$ was amplified from a subset of Platygyra daedalea, M. ampliata and Podabacia crustacea samples (as these species hosted the novel type) using the PSBA_NC_F and PSBA_NC_R primer pair (Smith et al. 2017c). The amplification was performed using the highfidelity enzyme Primerstar GXL according to the establish protocol for these primers (Smith et al. 2017c). Sequencing of the PCR products was performed at Bioneer (South Korea).

$\mathrm{PsbA}^{\mathrm{ncr}}$ chromatograms were visually inspected and were cropped according to the extent of unambiguous base calls as sequence quality rapidly deteriorates after poly-A/ $\mathrm{T}$ regions. Low quality sequences resulting from the presence of $\mathrm{psbA}^{\mathrm{ncr}}$ intragenomic or intergenomic variants were discarded. The resulting sequences (GenBank accession numbers: MT513104-MT513119) were manually aligned in MEGA X (Kumar et al. 2018) due to the presence of multiple large indels (Moore et al. 2003; LaJeunesse and Thornhill 2011). The sequence alignment was analysed with MrBayes (Ronquist et al. 2012) v3.2.6 using the Jukes-Cantor model. The MCMC was run for $2 \times 10^{6}$ generations, and sampled every 1000 generations with a burn-in of 0.25 . The majority $50 \%$ consensus tree was imported into ggtree (Yu et al. 2017) v2.0.2 for visualization. 


\section{Results and discussion}

Sequencing of the ITS2 amplicons yielded 25,869,576 raw demultiplexed reads. Merging of the overlapping reads resulted in 12,934,788 raw contigs, yielding 8,000,718 contigs after quality control from 438 individuals (mean: 18,266 contigs/individual). From these quality-controlled contigs, SymPortal identified 27 profiles (7 Cladocopium; 20 Durusdinium) within our dataset based on 28 DIVs (10 Cladocopium; 18 Durusdinium) (Figs. 2, 3).

Among the five coral species sampled across reefs in Singapore, only two symbiont genera were identified: Cladocopium and Durusdinium (Fig. 2), consistent with previous reports of symbiont communities in Singapore (Reimer and Todd 2009; Guest et al. 2016a; Tanzil et al. 2016) and other Indo-Pacific reef systems (Lien et al. 2007; Hennige et al. 2010; LaJeunesse et al. 2010; Ng and Ang 2016; Wong et al. 2016). However, the absence of genera such as Symbiodinium differs from other marginal environments, most notably in cases where Symbiodinium has been reported in conspecifics (Hume et al. 2015; Smith et al. 2017a, c; Ziegler et al. 2017). It has been suggested that stress-tolerant Durusdinium strains may play a crucial role in Singapore's reefs due to their association with warm, turbid reefs, and the apparent resilience of these reefs to multiple bleaching events (Guest et al. 2016a;
Tanzil et al. 2016). However, of the two Symbiodiniaceae genera observed, Cladocopium was the most common, accounting for $89 \%$ of the symbiont community, and the most dominant (i.e., accounting for $>50 \%$ of reads in the sample) genus observed in $91 \%$ of colonies. In contrast, Durusdinium was considerably less abundant, accounting for only $11 \%$ of the symbiont community (Fig. 2). The relative abundance of Durusdinium on Singapore reefs is lower than previous records for neighbouring reef provinces, including the Andaman Sea (relative Durusdinium abundance $\sim 35 \%$ ), where corals also experience high turbidity (LaJeunesse et al. 2010). This difference in Durusdinium abundance could be related to temporal changes in the symbiont community after bleaching events (e.g., Jones et al. 2008, but see McGinley et al. 2012, Smith et al. 2017a, Howells et al. 2020) or due to differences in sampled host taxa between studies (different host taxa may show a higher affinity for Durusdinium associations). Among our samples, we identified variation in Durusdinium abundance among coral species with the mean abundance ranging from $21 \pm 3 \%$ (mean $\pm \mathrm{SE}$ ) in Pectinia alcicornis to $3 \pm 1 \%$ (mean $\pm \mathrm{SE}$ ) in Platygyra daedalea. PERMANOVA analyses identified a significant species effect on the symbiont community (ESM Supplementary Table 1); therefore, caution should be taken when comparing across studies with different host taxa. Indeed,

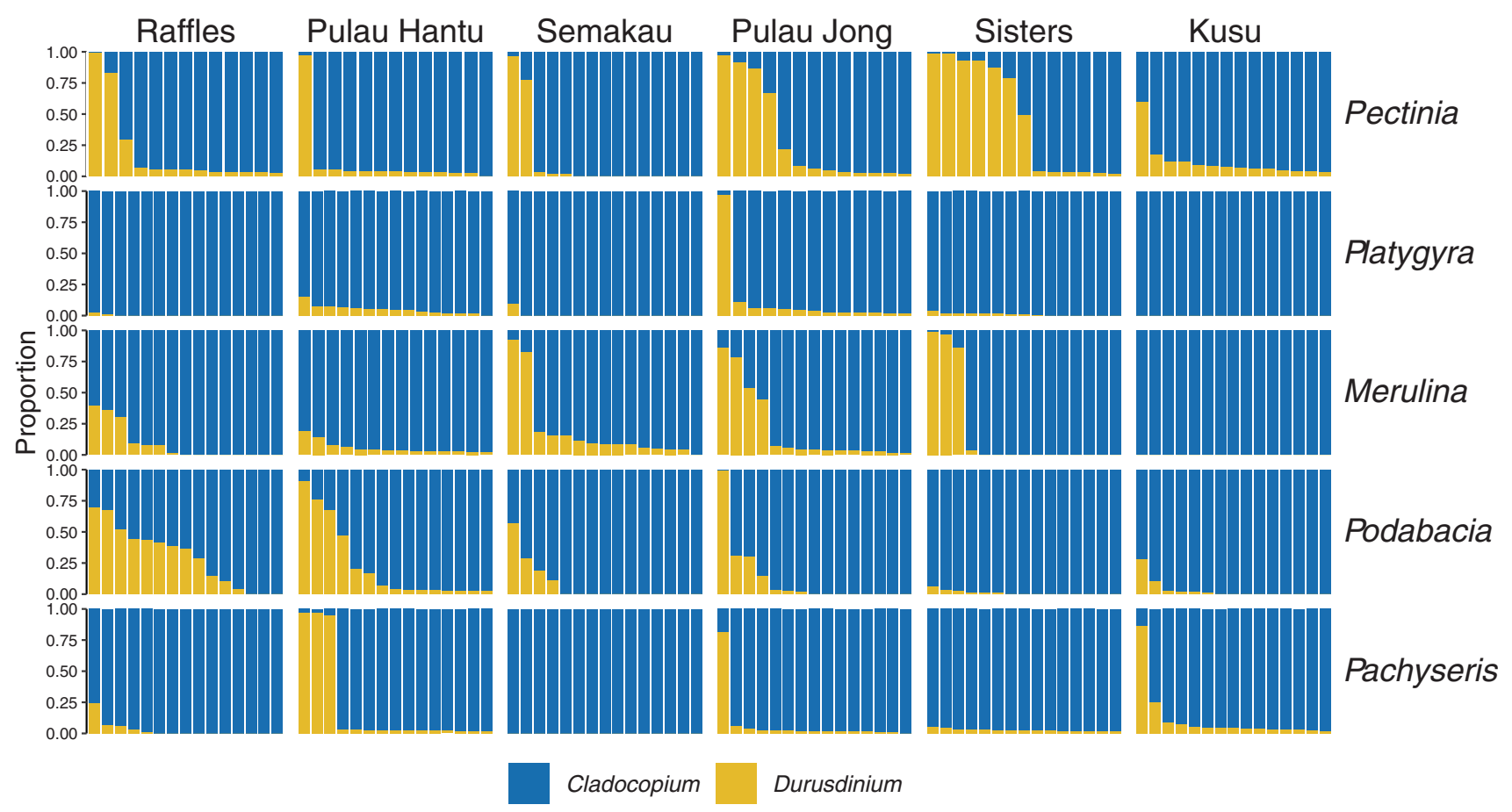

Fig. 2 Symbiodiniaceae genera composition of Singaporean corals. Each species-by-site section of the matrix plot is comprised of a series of stacked bar plots showing the relative composition of Cladocopium (blue) and Durusdinium (yellow) ITS2 sequences within a single sample. Each stacked bar represents a single individual 


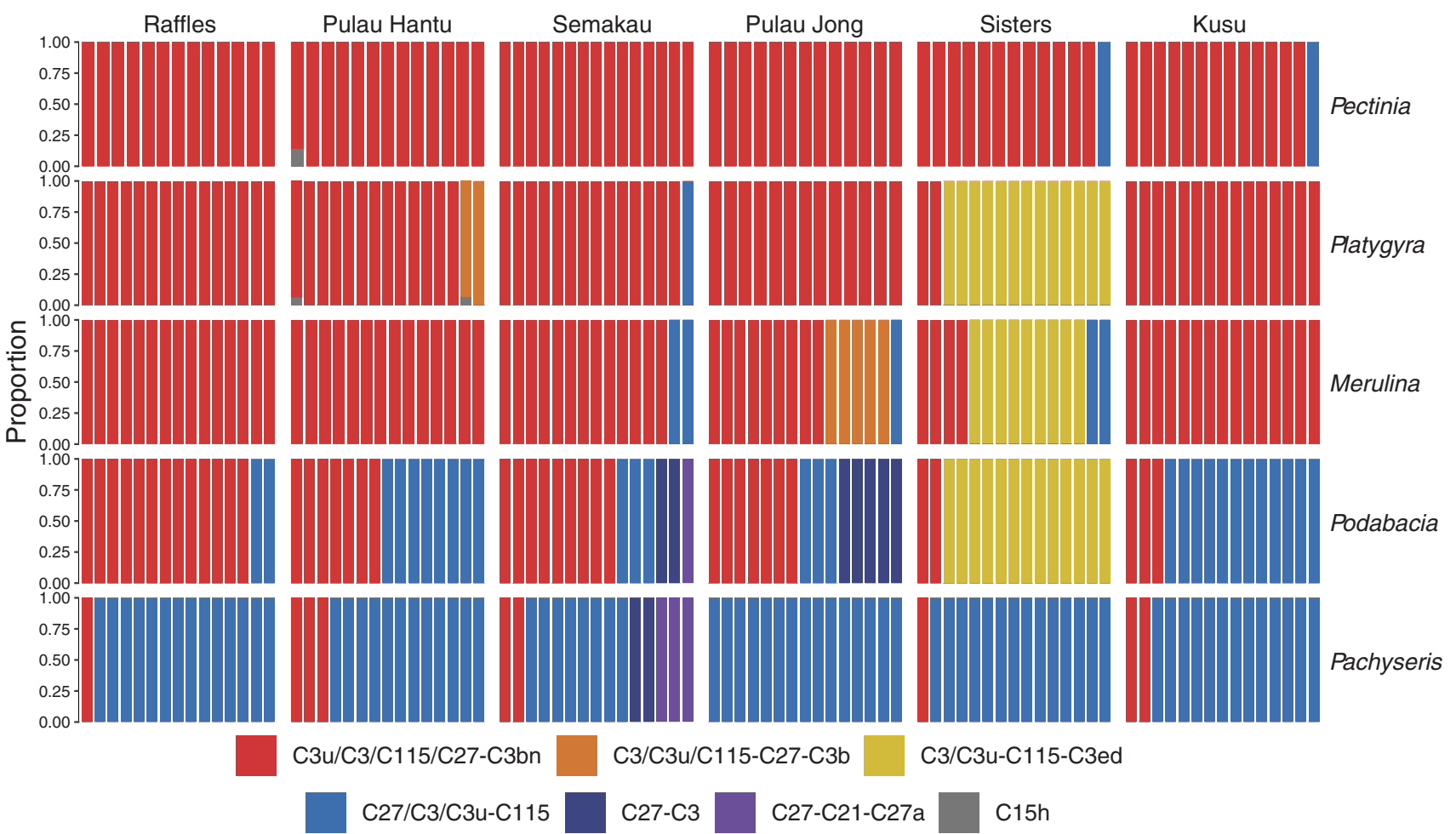

Fig. 3 Cladocopium profile composition of Singaporean corals. Each species-by-site section of the matrix plot is comprised of a series of stacked bar plots showing the relative proportion of the seven Cladocopium profiles within a sample. Each stacked bar represents a single individual

although we did not observe Durusdinium-dominated communities among our sampled taxa, there is evidence among a limited number of samples that Pocillopora acuta and Diploastrea heliopora colonies in Singaporean reefs may have high Durusdinium fidelity (Tanzil et al. 2016; Poquita-Du et al. 2020).

Using SymPortal (SymPortal.org), we found that the diversity of Durusdinium profiles were most likely from the stress-tolerant species, D. trenchii, due to the dominant cooccurrence of the D1 and D4 ITS2 sequences and presence across multiple hosts (ESM Supplementary Figure 1) (LaJeunesse et al. 2014). Of the 20 Durusdinium profiles identified, 17 were D1-4 derivatives while for two other profiles it was not possible to determine whether they belonged to the D1-4 or D1-4-6 lineage due to the differences in sensitivity between the DGGE method used for the original symbiont descriptions, and the amplicon approach used in the current study. Nevertheless, the occurrence of D. trenchii on Singapore's highly impacted, turbid reefs is consistent with previous studies showing elevated abundances of this species on marginal reefs (LaJeunesse et al. 2010; Keshavmurthy et al. 2014). Importantly, our observation of multiple $D$. trenchii profiles suggests further diversity within this important symbiont species. Additional sampling where $D$. trenchii is more abundant and the application of additional genetic markers (e.g., LaJeunesse et al. 2014) is warranted to better understand the ITS2 profile diversity and the distribution of these putative strains across different sites and species.

There were seven ITS2 profiles identified by SymPortal in the most abundant genus, Cladocopium (Fig. 3). Based on the UniFrac similarity between profiles (ESM Supplementary Figure 2), these profiles can be broadly split into three main groups, group A $(C 3 / C 3 u / C 115-C 27-C 3 b, C 3 /$ C3u-C115-C3ed, C3u/C3/C115/C27-C3bn), group B (C27$C 21-C 27 a, C 27-C 3, C 27 / C 3 / C 3 u-C 115)$ and group $\mathrm{C}$ (C15). PERMANOVA analyses of ITS2 profile composition indicated that host species had the greatest impact on the ITS2 profile community structure $\left(R^{2}=0.377\right.$; $p<0.001)$, with site $\left(R^{2}=0.113 ; p<0.001\right)$ and speciesby-site $\left(R^{2}=0.128 ; p<0.001\right)$ interactions also playing a significant role (ESM Supplementary Table 2). Rather than reflecting host-specific Symbiodiniaceae strains, the large proportion of variance attributed to the coral host describes the association of different host-generalist strains with different coral taxa. The group A profiles were widespread across samples from all sites for Pectinia alcicornis, $M$. ampliata and Platygyra daedalea, whereas group B profiles were the dominant profiles in Pachyseris speciosa samples. Podabacia crustacea hosted a combination of group A and 
Fig. 4 Chloroplast psbA ${ }^{\text {ncr }}$ phylogeny of Cladocopium samples classified to different ITS2 profiles by SymPortal. The tree was constructed through Bayesian inference using a Jukes-Cantor model. Samples are labelled according to site (RAF, Raffles; PHA, Pulau Hantu; SEM, Pulau Semakau; PJO, Pulau Jong; SIS, Sisters' Island; KUS, Kusu). Support for nodes is shown where the posterior probabilities exceed 0.8
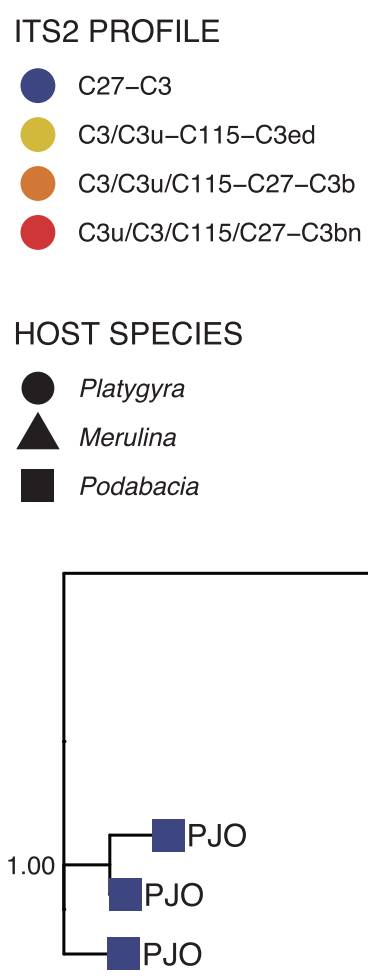

group B profiles potentially reflecting lower fidelity for specific strains in this coral species.

The number of distinct Cladocopium ITS2 profiles in this study of Singaporean corals is comparable to other studies employing SymPortal. For example, previous studies have identified five distinct Cladocopium ITS2 profiles from the Great Barrier Reef (GBR) and eight from the Red Sea (Camp et al. 2019; Terraneo et al. 2019). However, the reduced taxonomic scope (GBR: 2 coral genera; Red Sea; 1 genus) and fewer samples (GBR: $n=14$; Red Sea: $n=80$ ) in these studies suggest Cladocopium diversity in Singapore is lower than other regions (ESM Supplementary Figure 3). Indeed, a recent study from the Red Sea with a more comparable sampling design (seven host species, six sites, $n=603$ ) identified 74 Cladocopium ITS2 profiles (Hume et al. 2020). Low Cladocopium diversity on reefs with high coral species diversity is notable for two reasons. First, it suggests that while the refuge effect of a low light environment may help maintain coral species diversity, it may not support diverse symbiont communities. Secondly, these patterns of diversity are in stark contrast to other marginal reef systems (LaJeunesse et al. 2008; Wicks et al. 2010), such as the Persian/Arabian Gulf where few coral species associate with a diverse Cladocopium lineage, C. thermophilum (Hume et al. 2016, 2018a; Smith et al. 2017b). The host specificity of Cladocopium strains found in the Persian/ Arabian Gulf (Smith et al. 2017b; Howells et al. 2020), and other marginal reefs (LaJeunesse et al. 2008), were not observed in Singapore, where single strains (represented by an ITS2 profile) are found across multiple host species (e.g., C3u/C3/C115/C27-C3bn). The distinct differences in the symbiont diversity among these marginal environments may be reflective of the duration under which these reefs have been exposed to stressful conditions. The high turbidity on Singapore's reefs is a relatively recent phenomenon, occurring as a consequence of increasing anthropogenic activities over the past 60 yrs (Chia et al. 1988; Dikou and Van Woesik 2006). Conversely, the Persian/Arabian Gulf has experienced thermally extreme conditions for $\sim 4000 \mathrm{yrs}$, providing greater opportunity for adaptive radiation in the symbiont community (Hume et al. 2016).

Despite low diversity of the Cladocopium communities in Singapore, we found a distinct Cladocopium ITS2 profile at Sisters' Island. To verify that the Sisters' Island associated ITS2 profile was distinct from other closely related profiles, we sequenced the $\mathrm{psbA}^{\mathrm{ncr}}$ for a subset of samples. Coral samples from Sisters' Island formed a monophyletic clade in our psbA ${ }^{\text {ncr }}$ tree (Fig. 4), in agreement with the distinct SymPortal ITS2 profile. Across an alignment of 427 nucleotides, the Sisters' Island samples shared two nucleotide substitutions that were distinct from all other samples. A similar degree of $\mathrm{psbA}^{\text {ncr }}$ sequence differentiation was observed between strains inferred using ITS2 metahaplotype approach (Smith et al. 2017b), highlighting the utility of the $\mathrm{psbA}^{\mathrm{ncr}}$ to provide additional support for closely related strains identified through ITS2 
intragenomic variant-based analyses. The cause of the apparent site specificity of this profile is unclear as Sisters' Island is not located at the geographic extremes of our sampling regime and because all sites are within $16 \mathrm{~km}$ of each other. Fine-scale differences in Cladocopium genotypes over short distances (tens of kilometres) have been observed in other marginal environments and were linked to local environmental conditions (Noda et al. 2017; Hume et al. 2018a). Deployment of in situ loggers to assess key environmental parameters (temperature, light, salinity) will help elucidate microhabitat differences and the potential environmental drivers for fine-scale differences observed in this study.

This study provides the most comprehensive survey of Symbiodiniaceae in Singaporean corals to date, covering five of the most locally dominant coral species at six reef sites. We show that a few host-generalist Cladocopium symbionts dominate the symbiont community and that the less abundant Durusdinium community is diverse, consisting of multiple D. trenchii strains. The higher taxonomic resolution afforded by SymPortal identified finescale differences in the Singaporean Symbiodiniaceae communities that would have been undetected by previous techniques. Our analyses highlight that as our resolution improves, fine-scale environmental data will be needed to help understand drivers of diversity on local and regional scales. As the high-resolution ITS2 analyses become more widespread and the usage of SymPortal framework increases, it will be possible to identify emerging trends with regard to important aspects of symbioses, such as the prevalence of local adaptive radiations in marginal environments and the timescales over which they arise.

Acknowledgements This research was partially carried out using the Core Technology Platforms resources at New York University Abu Dhabi, including the High Performance Computing Cluster and Sequencing Core Technology Platforms. Collection of coral samples was authorized by Singapore National Parks (NP/RP15-061). We would like to thank the Agri-Food and Veterinary Authority of Singapore for providing CITES export permit 15SG012731CE, and the UAE Ministry of Environment and Climate Change for providing the CITES import permit 15MEW4457. This study was supported by the AXA Fellowship (R-154-000-649-507) to AGB and the National Research Foundation, Prime Minister's Office, Singapore under the Marine Science Research and Development Programme (R-154-001A25-281 MSRDP-P03).

\section{Compliance with ethical standards}

Conflict of interest On behalf of all authors, the corresponding author states that there is no conflict of interest.

\section{References}

Anderson MJ, Walsh DC (2013) PERMANOVA, ANOSIM, and the Mantel test in the face of heterogeneous dispersions: what null hypothesis are you testing? Ecol Monogr 83:557-574

Bongaerts P, Riginos C, Ridgway T, Sampayo EM, van Oppen MJ, Englebert N, Vermeulen F, Hoegh-Guldberg O (2010) Genetic divergence across habitats in the widespread coral Seriatopora hystrix and its associated Symbiodinium. PLoS ONE 5:e10871

Brown BE (1997) Coral bleaching: causes and consequences. Coral Reefs 16:S129-S138

Bruno JF, Selig ER (2007) Regional decline of coral cover in the Indo-Pacific: timing, extent, and subregional comparisons. PLoS ONE 2:e711

Cacciapaglia C, van Woesik R (2016) Climate-change refugia: shading reef corals by turbidity. Glob Chang Biol 22:1145-1154

Camp EF, Schoepf V, Mumby PJ, Hardtke LA, Rodolfo-Metalpa R, Smith DJ, Suggett DJ (2018) The future of coral reefs subject to rapid climate change: lessons from natural extreme environments. Front Mar Sci 5:4

Camp EF, Edmondson J, Doheny A, Rumney J, Grima AJ, Huete A, Suggett DJ (2019) Mangrove lagoons of the Great Barrier Reef support coral populations persisting under extreme environmental conditions. Mar Ecol Prog Ser 625:1-14

Catchen J, Hohenlohe PA, Bassham S, Amores A, Cresko WA (2013) Stacks: an analysis tool set for population genomics. Mol Ecol 22:3124-3140

Chia LS, Khan H, Chou LM (1988) The coastal environmental profile of Singapore. WorldFish

D'Angelo C, Hume BC, Burt J, Smith EG, Achterberg EP, Wiedenmann J (2015) Local adaptation constrains the distribution potential of heat-tolerant Symbiodinium from the Persian/ Arabian Gulf. ISME J 9:2551

Dana JD (1846) Zoophytes. In: Wilkes C (ed) United States Exploring Expedition During the years 1838, 1839, 1840, 1841, 1842. Lea and Blanchard, Philadelphia, pp 1-740

De'ath G, Fabricius KE, Sweatman H, Puotinen M (2012) The 27year decline of coral cover on the Great Barrier Reef and its causes. Proc Natl Acad Sci USA 109:17995-17999

Dikou A, Van Woesik R (2006) Survival under chronic stress from sediment load: spatial patterns of hard coral communities in the southern islands of Singapore. Mar Pollut Bull 52:1340-1354

Ellis J, Solander DC (1786) The natural history of many curious and uncommon zoophytes: collected from various parts of the globe. Benjamin White and Son, and Peter Elmsly, London

Eren AM, Morrison HG, Lescault PJ, Reveillaud J, Vineis JH, Sogin ML (2015) Minimum entropy decomposition: unsupervised oligotyping for sensitive partitioning of high-throughput marker gene sequences. ISME J 9:968

Fabricius K, Mieog J, Colin P, Idip D, Van Oppen M (2004) Identity and diversity of coral endosymbionts (zooxanthellae) from three Palauan reefs with contrasting bleaching, temperature and shading histories. Mol Ecol 13:2445-2458

Glynn PW (1983) Extensive 'bleaching'and death of reef corals on the Pacific coast of Panama. Environ Conserv 10:149-154

Guest J, Low J, Tun K, Wilson B, Ng C, Raingeard D, Ulstrup K, Tanzil JTI, Todd P, Toh T (2016a) Coral community response to bleaching on a highly disturbed reef. Sci Rep 6:20717

Guest J, Tun K, Low J, Vergés A, Marzinelli E, Campbell AH, Bauman A, Feary D, Chou L, Steinberg P (2016b) 27 years of benthic and coral community dynamics on turbid, highly urbanised reefs off Singapore. Sci Rep 6:36260

Hennige SJ, Smith DJ, Walsh S-J, McGinley MP, Warner ME, Suggett DJ (2010) Acclimation and adaptation of scleractinian 
coral communities along environmental gradients within an Indonesian reef system. J Exp Mar Bio Ecol 391:143-152

Hoegh-Guldberg O, Mumby PJ, Hooten AJ, Steneck RS, Greenfield P, Gomez E, Harvell CD, Sale PF, Edwards AJ, Caldeira K (2007) Coral reefs under rapid climate change and ocean acidification. Science 318:1737-1742

Howells EJ, Abrego D, Meyer E, Kirk NL, Burt JA (2016) Host adaptation and unexpected symbiont partners enable reef-building corals to tolerate extreme temperatures. Glob Chang Biol 22:2702-2714

Howells EJ, Bauman AG, Vaughan GO, Hume BC, Voolstra CR, Burt JA (2020) Corals in the hottest reefs in the world exhibit symbiont fidelity not flexibility. Mol Ecol 29:899-911

Huang D, Tun KP, Chou LM, Todd PA (2009) An inventory of zooxanthellate scleractinian corals in Singapore, including 33 new records. Raffles Bulletin of Zoology 22:69-80

Huang D, Benzoni F, Fukami H, Knowlton N, Smith ND, Budd AF (2014) Taxonomic classification of the reef coral families Merulinidae, Montastraeidae, and Diploastraeidae (Cnidaria: Anthozoa: Scleractinia). Zool J Linn Soc 171:277-355

Hume B, D'angelo C, Burt J, Baker A, Riegl B, Wiedenmann J (2013) Corals from the Persian/Arabian Gulf as models for thermotolerant reef-builders: prevalence of clade C3 Symbiodinium, host fluorescence and ex situ temperature tolerance. Mar Pollut Bull $72: 313-322$

Hume BC, D'Angelo C, Smith EG, Stevens JR, Burt J, Wiedenmann J (2015) Symbiodinium thermophilum sp. nov., a thermotolerant symbiotic alga prevalent in corals of the world's hottest sea, the Persian/Arabian Gulf. Sci Rep 5:8562

Hume BC, Voolstra CR, Arif C, D'Angelo C, Burt JA, Eyal G, Loya Y, Wiedenmann J (2016) Ancestral genetic diversity associated with the rapid spread of stress-tolerant coral symbionts in response to Holocene climate change. Proc Natl Acad Sci U S A 113:4416-4421

Hume BC, D'Angelo C, Burt JA, Wiedenmann J (2018a) Fine-scale biogeographical boundary delineation and sub-population resolution in the Symbiodinium thermophilum coral symbiont group from the Persian/Arabian Gulf and Gulf of Oman. Front Mar Sci $5: 138$

Hume BC, Ziegler M, Poulain J, Pochon X, Romac S, Boissin E, De Vargas C, Planes S, Wincker P, Voolstra CR (2018b) An improved primer set and amplification protocol with increased specificity and sensitivity targeting the Symbiodinium ITS2 region. PeerJ 6:e4816

Hume BC, Smith EG, Ziegler M, Warrington HJ, Burt JA, LaJeunesse TC, Wiedenmann J, Voolstra CR (2019) SymPortal: a novel analytical framework and platform for coral algal symbiont nextgeneration sequencing ITS2 profiling. Mol Ecol Resour 19:1063-1080

Hume BC, Mejia-Restrepo A, Voolstra CR, Berumen ML (2020) Fine-scale delineation of Symbiodiniaceae genotypes on a previously bleached central Red Sea reef system demonstrates a prevalence of coral host-specific associations. Coral Reefs $1-19$

Iglesias-Prieto R, Beltran V, Lajeunesse TC, Reyes-Bonilla H, Thome P (2004) Different algal symbionts explain the vertical distribution of dominant reef corals in the eastern Pacific. Proc Biol Sci 271:1757-1763

Jones AM, Berkelmans R, van Oppen MJ, Mieog JC, Sinclair W (2008) A community change in the algal endosymbionts of a scleractinian coral following a natural bleaching event: field evidence of acclimatization. Proc Biol Sci 275:1359-1365

Keshavmurthy S, Meng P-J, Wang J-T, Kuo C-Y, Yang S-Y, Hsu C-M, Gan C-H, Dai C-F, Chen CA (2014) Can resistant coralSymbiodinium associations enable coral communities to survive climate change? A study of a site exposed to long-term hot water input. PeerJ 2:e327

Kleypas JA, McManus JW, Menez LA (1999) Environmental limits to coral reef development: where do we draw the line? Am Zool 39:146-159

Kumar S, Stecher G, Li M, Knyaz C, Tamura K (2018) MEGA X: molecular evolutionary genetics analysis across computing platforms. Mol Biol Evol 35:1547-1549

LaJeunesse TC, Thornhill DJ (2011) Improved resolution of reefcoral endosymbiont (Symbiodinium) species diversity, ecology, and evolution through psbA non-coding region genotyping. PLoS ONE 6:e29013

LaJeunesse TC, Bonilla HR, Warner M, Wills M, Schmidt G, Fitt W (2008) Specificity and stability in high latitude eastern Pacific coral-algal symbioses. Limnol Oceanogr 53:719-727

LaJeunesse TC, Wham DC, Pettay DT, Parkinson JE, Keshavmurthy S, Chen CA (2014) Ecologically differentiated stress-tolerant endosymbionts in the dinoflagellate genus Symbiodinium (Dinophyceae) Clade D are different species. Phycologia 53:305-319

LaJeunesse TC, Parkinson JE, Gabrielson PW, Jeong HJ, Reimer JD, Voolstra CR, Santos SR (2018) Systematic revision of Symbiodiniaceae highlights the antiquity and diversity of coral endosymbionts. Curr Biol 28(2570-2580):e2576

LaJeunesse TC, Pettay DT, Sampayo EM, Phongsuwan N, Brown B, Obura DO, Hoegh-Guldberg O, Fitt WK (2010) Long-standing environmental conditions, geographic isolation and host-symbiont specificity influence the relative ecological dominance and genetic diversification of coral endosymbionts in the genus Symbiodinium. J Biogeogr 37:785-800

Lesser MP, Slattery M, Stat M, Ojimi M, Gates RD, Grottoli A (2010) Photoacclimatization by the coral Montastraea cavernosa in the mesophotic zone: light, food, and genetics. Ecology 91:990-1003

Lien Y-T, Nakano Y, Plathong S, Fukami H, Wang J-T, Chen C (2007) Occurrence of the putatively heat-tolerant Symbiodinium phylotype D in high-latitudinal outlying coral communities. Coral Reefs 26:35-44

McGinley MP, Aschaffenburg MD, Pettay DT, Smith RT, LaJeunesse TC, Warner ME (2012) Symbiodinium spp. in colonies of eastern Pacific Pocillopora spp. are highly stable despite the prevalence of low-abundance background populations. Mar Ecol Prog Ser $462: 1-7$

Moore RB, Ferguson KM, Loh WK, Hoegh-Guldberg O, Carter DA (2003) Highly organized structure in the non-coding region of the psbA minicircle from clade C Symbiodinium. Int J Syst Evol Microbiol 53:1725-1734

Morgan KM, Perry CT, Johnson JA, Smithers SG (2017) Nearshore turbid-zone corals exhibit high bleaching tolerance on the Great Barrier Reef following the 2016 ocean warming event. Front Mar Sci 4:224

Muscatine L, Porter JW (1977) Reef corals: mutualistic symbioses adapted to nutrient-poor environments. Bioscience 27:454-460

Ng TY, Ang P (2016) Low symbiont diversity as a potential adaptive strategy in a marginal non-reefal environment: a case study of corals in Hong Kong. Coral Reefs 35:941-957

Noda H, Parkinson JE, Yang S-Y, Reimer JD (2017) A preliminary survey of zoantharian endosymbionts shows high genetic variation over small geographic scales on Okinawa-jima Island, Japan. PeerJ 5:e3740

Oksanen J, Blanchet FG, Friendly M, Kindt R, Legendre P, McGlinn D, Minchin PR, O'Hara RB, Simpson GL, Solymos P, Stevens MHH, Szoecs E, Wagner H (2019) vegan: Community Ecology Package. R package version 2.5-6

Oliver T, Palumbi S (2011) Many corals host thermally resistant symbionts in high-temperature habitat. Coral Reefs 30:241-250 
Pallas PS (1766) Elenchus zoophytorum sistens generum adumbrationes generaliores et specierum cognitarum... descriptiones etc. Varrentrapp, Den Haag

Poquita-Du RC, Huang D, Chou LM, Todd PA (2020) The contribution of stress-tolerant endosymbiotic dinoflagellate $\mathrm{Du}$ rusdinium to Pocillopora acuta survival in a highly urbanized reef system. Coral Reefs 1-11

R Core Team (2019) R: A language and environment for statistical computing. Austria, Vienna

Reimer JD, Todd PA (2009) Preliminary molecular examination of zooxanthellate zoanthid (Hexacorallia, Zoantharia) and associated zooxanthellae (Symbiodinium spp.) diversity in Singapore. Raffles Bulletin of Zoology 22:103-120

Ronquist F, Teslenko M, Van der Mark P, Ayres DL, Darling A, Höhna S, Larget B, Liu L, Suchard MA, Huelsenbeck JP (2012) MrBayes 3.2: efficient Bayesian phylogenetic inference and model choice across a large model space. Syst Biol 61:539-542

Saville Kent W (1871) On some new and little known species of Madreporaria, or stony corals, in the British Museum collection. Proceedings of the Zoological Society of London 2:275-286

Schloss PD, Westcott SL, Ryabin T, Hall JR, Hartmann M, Hollister EB, Lesniewski RA, Oakley BB, Parks DH, Robinson CJ (2009) Introducing mothur: open-source, platform-independent, community-supported software for describing and comparing microbial communities. Appl Environ Microbiol 75:7537-7541

Smith EG, Vaughan GO, Ketchum RN, McParland D, Burt JA (2017a) Symbiont community stability through severe coral bleaching in a thermally extreme lagoon. Sci Rep 7:2428

Smith EG, Ketchum RN, Burt JA (2017b) Host specificity of Symbiodinium variants revealed by an ITS2 metahaplotype approach. ISME J 11:1500-1503

Smith EG, Hume BC, Delaney P, Wiedenmann J, Burt JA (2017c) Genetic structure of coral-Symbiodinium symbioses on the world's warmest reefs. PLoS ONE 12:e180169

Smith EG, D'angelo C, Sharon Y, Tchernov D, Wiedenmann J (2017d) Acclimatization of symbiotic corals to mesophotic light environments through wavelength transformation by fluorescent protein pigments. Proc Biol Sci 284:20170320

Stambler N, Dubinsky Z (2005) Corals as light collectors: an integrating sphere approach. Coral Reefs 24:1-9
Tanzil JTI, Ng APK, Tey YQ, Tan BHY, Yun EY, Huang D (2016) A preliminary characterisation of Symbiodinium diversity in some common corals from Singapore. Cosmos 12:15-27

Terraneo TI, Fusi M, Hume BC, Arrigoni R, Voolstra CR, Benzoni F, Forsman ZH, Berumen ML (2019) Environmental latitudinal gradients and host-specificity shape Symbiodiniaceae distribution in Red Sea Porites corals. J Biogeogr 46:2323-2335

Todd PA, Ladle RJ, Lewin-Koh N, Chou LM (2004) Genotype $\times$ environment interactions in transplanted clones of the massive corals Favia speciosa and Diploastrea heliopora. Mar Ecol Prog Ser 271:167-182

Toller WW, Rowan R, Knowlton N (2001) Zooxanthellae of the Montastraea annularis species complex: patterns of distribution of four taxa of Symbiodinium on different reefs and across depths. Biol Bull 201:348-359

Veron JE, Stafford-Smith M, Turak E, DeVantier L (2015) Corals of the World (http://www.coralsoftheworld.org/)

Wicks L, Sampayo E, Gardner J, Davy S (2010) Local endemicity and high diversity characterise high-latitude coral-Symbiodinium partnerships. Coral Reefs 29:989-1003

Wilkinson C (2008) Status of coral reefs of the world: 2008. Global Coral Reef Monitoring Network and Reef and Rainforest Research Centre, Townsville

Wong JC, Thompson P, Xie JY, Qiu J-W, Baker DM (2016) Symbiodinium clade $\mathrm{C}$ generality among common scleractinian corals in subtropical Hong Kong. Reg Stud Mar Sci 8:439-444

Yu G, Smith DK, Zhu H, Guan Y, Lam TTY (2017) GGTREE: an R package for visualization and annotation of phylogenetic trees with their covariates and other associated data. Methods Ecol Evol 8:28-36

Ziegler M, Arif C, Burt JA, Dobretsov S, Roder C, LaJeunesse TC, Voolstra CR (2017) Biogeography and molecular diversity of coral symbionts in the genus Symbiodinium around the Arabian Peninsula. J Biogeogr 44:674-686 